\title{
Report (1966-1970) of the Subcommittee on Phage-Typing of Staphylococci to the International Committee on Nomenclature of Bacteria
}

\author{
13 August 1970
}

Mexico City, Mexico

This report describes the work of the Subcommittee during the years 1966-1970 and includes a summary of the decisions taken at its 5 th meeting, which was held in Mexico City on 6 August 1970.

1. Membership and officers. The Subcommittee consists of a Chairman, a Secretary, 43 representatives of national staphylococcus phage-typing laboratories, and two co-opted members. E. H. Asheshov replaced M. T. Parker as Secretary in August 1970. The full list of the present membership is as follows: L. Arcalis, Barcelona, Spain; A. Arseni, Athens, Greece; E. H. Asheshov, London, England; J. Beumer, Brussels, Belgium; H. Brandis, Bonn, Germany; E. T. Çetin, Istanbul, Turkey; Chang, Chendu, Szechwan, China; Doki Chun, Taegu, Republic of Korea; Vu Qui Dai, Saigon, South Vietnam; Ian Davidson, New Haw, Weybridge, Surrey, England; J-M. Fouace, Paris, France; T. H. Fuh, Taipei, Taiwan, Formosa; Y. A. El Batawi, Cairo, Egypt; R. Gharagozloo, Teheran, Iran; H. K. Ghosh, Kuala Lumpur, Malaysia; M. Grigorova, Sofia, Bulgaria; W. Harris, Ot tawa, Canada; Y. Hermon, Colombo, Ceylon; K. Ishihara, Maebashi, Japan; L. O. Kallings, Stockholm, Sweden; H. T. Knights, Wellington, S. I., New Zealand; H. J. Koornhof, Johannesburg, South Africa; S. Kryński, Gdańsk, Poland; A. M. Marquez, Montevideo, Uruguay, V. Matèjovska, Prague, Czechoslovakia; W. Meyer, Wernigerode, Germany; H. Milch, Budapest, Hungary; M. Moreira-Jacob, Lisbon, Portugal; P. Oeding, Bergen, Norway; V. Ortali, Rome, Italy; M. T. Parker, London, England; M. Popovici, Bucharest, Romania; I. Rantasalo, Helsinki, Finland; B. Ghosh Ray, New Delhi, India; H. Reber, Basel, Switzerland; H. Rische, Wernigerode, Germany; M. Rodriguez-Leiva, Santiago, Chile; K. Rosendal, Copenhagen, Denmark; P. M. Rountree, Camperdown, N.S.W., Australia (Chairman); L. E. Sanchez-Torres, Mexico City, Mexico; L.S. Saubert de Allegroni, Buenos Aires, Argentina; R. Th. Scholtens, Utrecht, The Netherlands; R. Skalova, Zagreb, Yugoslavia; P. Byrd Smith, Atlanta, Georgia, USA; D. Sompolinsky, Tel-
Aviv, Israel; and G. Vygodchikov, Moscow, USSR.

The Staphylococcus Reference Laboratory at the Central Public Health Laboratory, Colindale, London, NW9, England, acts as WHO International Centre for Staphylococcus PhageTyping.

2. International standardization. For many years the International Centre has at stated intervals provided fresh stocks of the typing phages and their propagating strains to each national laboratory. It is the responsibility of the national laboratories to propagate these phages and issue them to other workers in their respective countries. Until recently, the determination of the lytic spectrum of the propagated phages on a series of test staphylococci (1) provided the main check on the host-range of the phages. Since 1969, however, high-titer preparations of the basic set of phages have been issued. The contents of one ampoule can be used not only for propagation but also to provide a reference standard for the lytic spectrum of the locally prepared phage. It is therefore now possible to decide whether a deviation from the accepted lytic spectrum is due to variation in the phage (or in its propagating strain or in the test strains) or to differences in the medium used in two laboratories.

Since 1952, international comparative tests of phage-typing have been carried out every 4 years. These tests proved to be a valuable means of drawing attention to discrepancies between the results of typing in different laboratories but gave little indication of their cause. Analysis of the results of the 5th Comparative Test (1969) suggested, however, that differences in the carrying out of the typing test rather than in the specificity of the phages used were the main source of discrepancies.

At the same time, investigations at the International Centre suggested that the susceptibility of some staphylococcal strains to lysis by the typing phages was influenced by small differences in the composition of the typing 
medium. The main variable appeared to be the type of agar used rather than the composition of the nutrient base.

The 5th meeting of the Subcommittee considered that it is not yet possible to specify a standard medium that could be made from universally available ingredients but urged that the medium used in each country should as far as possible be uniform in composition. The comparative tests should be continued.

3. Optimum strength of phages for typing. The internationally accepted procedure for phage-typing of staphylococci has been to test each culture first with the basic set of phages at the routine test dilution (RTD) and to re-test all cultures that were untypable at RTD with 1,000 -times stronger preparations of the same phages (RTD $\times 1,000)$, except that phages $83 \mathrm{~A}, 84$, and 85 are used only at RTD (6).

The results of typing with phages at RTD $\times 1,000$ are, however, somewhat unsatisfactory, and some members of the Subcommittee felt that the use of a somewhat lower concentration of phage would improve the reproducibility of the test without greatly reducing the percentage of typable cultures. $R$. Skalova (Yugoslavia) agreed to form a working group to study this problem (6). A study of the reproducibility of typing results with phages at different strengths was carried out by 20 national laboratories, and the results were presented to the 5th meeting of the Subcommittee. These showed (i) that reproducibility was considerably better with phages at RTD $\times 100$ than at RTD $\times 1,000$, mainly due to a reduction in the number of inhibition reactions and (ii) that the reduction in the percentage of typable cultures was acceptable and was offset by the increased precision of the results at RTD $\times 100$ and by the fact that reliance could be placed on weak reactions with this strength of phage. The results of this study will be published in full.

The Subcommittee resolved that in the future the recommended typing procedure would be the following: (i) typing with the basic-set phages at RTD; and (ii) typing of cultures not lysed by any of the basic-set phages at RTD with the same phages, except $83 \mathrm{~A}, 84$, and 85 , at RTD $\times 100$.

4. Composition of the basic set of phages for typing human strains of Staphylococcus aureus. Changes are made in the composition of the basic set of typing phages from time to time to ensure that the greatest possible number of strains of $S$. aureus are typable. The successive appearance in hospitals of new strains of antibiotic-resistant staphylococci has necessi- tated the introduction of several new phages into the set. Phages 80 and 81 were introduced to characterize members of the " $52,52 \mathrm{~A}, 80$, 81 complex" of phage-group I strains that became worldwide in distribution between 1954 and 1960. In the period 1958 to 1966, further new untypable strains appeared that were subsequently shown to belong to phagegroup III. The phages $83 \mathrm{~A}, 84$, and 85 proved valuable for characterizing these strains in many but not in all countries. The staphylococci lysed by these phages form a "complex" of rather similar but not identical staphylococci, and certain culturally similar strains were not lysed by the newer phages. Most of the strains prevalent in the USA, for example, were not lysed by phages $83 \mathrm{~A}, 84$, or 85 , but were lysed by phage 86 (no. UC18). This phage and phage 87 (no. 1380), which lyses a quite different hospital strain apparently confined to Hungary and neighboring countries, were not included in the basic set on the grounds that they appeared to be of value only in a limited geographical area, but both have been used locally as additional phages.

The main event since 1966 has been the widespread appearance of further strains that are difficult to phage-type and are usually resistant to methicillin. They appear to fall into two broad groups. Members of the first group are untypable with basic-set phages but, like the strains of the " $83 \mathrm{~A}, 84,85$ complex," give inhibition reactions with group III phages at RTD $\times 1,000$. Members of the second group give similar inhibition reactions with group-III phages but are lysed inconstantly, though sometimes at RTD, by the group-I phages 29 and 79 . The search for phages to characterize these strains has been only partially successful. Phages have been found that lyse most of the cultures from one hospital, or even from one country. The strains prevalent in Denmark are mainly of the first group, and most of them are lysed by phage 89 (no. 592). This phage lyses a much smaller proportion of similar strains found in Britain. Phage 88 lyses a high proportion of methicillin-resistant strains of both groups prevalent in Britain, but few strains from elsewhere in Europe. Several other phages with somewhat similar spectra of activity are at present under investigation, but so far none appears to be useful over a wide geographical area.

The Subcommittee considered this situation at its 5th meeting and decided not to recommend any change in the composition of the basic set of phages, which therefore remains as follows: Group I-29, 52, 52A, 79, 80; Group 
II-3A, 3C, 55, 71; Group III-6, 42E, 47, 53, $54,75,77,83 \mathrm{~A}$ (used only at RTD), 84 , (used only at RTD), 85 (used only at RTD); Group IV-42D. Not allotted-81, 187.

5. Phage-typing of bovine staphylococci. At its 4th meeting, the Subcommittee set up a working group under the chairmanship of $I$. Davidson to study the phage-typing of $S$. aureus strains of bovine origin and to make recommendations on the constitution of a basic set of phages for this purpose. This group carried out an investigation with the collaboration of veterinary bacteriologists in 17 centers and reported to the Subcommittee in 1970. They proposed the establishment of a basic set of 16 phages, including 9 members of the present "human" basic set and 7 other phages. Their recommendations were accepted by the Subcommittee, who also requested the Working Group to remain in being to coordinate studies and designated the Central Veterinary Laboratory at Wey bridge, England, as coordinating laboratory for the phage-typing of bovine staphylococci.

6. Nomenclature of phages. Two basic sets of phages have now been of ficially recognized for typing $S$. aureus, and others may be added in the future. The term "basic set" should therefore always be qualified. It is generally recognized that the original basic set is used mainly for typing $S$. aureus cultures of human origin. It should be so described to distinguish it from the set of phages used for typing bovine staphylococci.

To avoid confusion, a single numbering system will be used for all phages in both typing systems as well as for all additional phages that have been examined at the International Centre and issued to other laboratories for testing. Four of the basic set of "bovine" phages have therefore been renumbered. These are listed below, together with other phages to which official numbers have been given since 1966.

7. Taxonomic implications of staphylococcus phage-typing. Staphylococcus phagetyping was first developed for the study of $S$. aureus strains from infections of man. Separate phage-typing systems have since been proposed for the subdivision of $S$. aureus strains from other animal hosts. It is now recognized that the $S$. aureus strains found in several mammalian species form distinct populations and that these may differ both in their susceptibility to phages and in their cultural characters. The classification of coagulase-negative staphylococci and micrococci by phage-typing is under investigation, and there is some evidence that subdivisions originally made in these groups on the basis of cultural and biochemical characters may be reflected in differences in susceptibility to the action of phages.

In the future, therefore, phage "typing" may be used to distinguish between (i) strains of $S$. aureus from the same animal host, as in the present "human" and "bovine" phage-typing systems, (ii) strains of $S$. aureus from different animal hosts, and (iii) different sorts of staphylococci and micrococci.

The Subcommittee considered these possibilities at its 5th meeting and concluded that its main responsibility was the standardization and further development of the present system for the phage-typing of human strains of $S$. aureus. Groups concerned with other uses of phage for the classification of staphylococci and micrococci might be expected to appear and develop along parallel lines. Close contact should be

TABLE 1. Typing phages given official numbers since 1966

\begin{tabular}{|c|c|c|c|c|}
\hline $\begin{array}{c}\text { Official } \\
\text { no. }\end{array}$ & $\begin{array}{l}\text { Formerly } \\
\text { known as }\end{array}$ & Received from & Reference & Status \\
\hline 88 & $\mathrm{C} 6$ & J. Bullimore, Colindale, London & & \\
\hline 89 & 592 & K. Rosendal, Copenhagen & Bulow (3) & \\
\hline 90 & B49 & H. D. Landau, Belfast & & Additional phages for \\
\hline 91 & M1 & M. Popovici, Bucarest & Popovici et al. (5) & "human" typing set $a$ \\
\hline 92 & 8906 & J. H. Hewitt, Colindale, London & & \\
\hline 93 & 6557 & K. Rosendal, Copenhagen & Bülow (2) & \\
\hline 116 & 883 & I. Davidson, Weybridge, England & Nakagawa (4) & Basic-set phages for \\
\hline 117 & $1363 / 14$ & I. Davidson, Weybridge, England & Smith (8) & typing bovine staphylococci \\
\hline 118 & S1 & I. Davidson, Weybridge, England & Seto and Wilson (7) & \\
\hline 119 & S6 & I. Davidson, Weybridge, England & Seto and Wilson (7) & \\
\hline
\end{tabular}

$a$ Under investigation for recognition of certain antibiotic-resistant strains found in hospitals. 
maintained between these groups, preferably through the Subcommittee on the Taxonomy of Staphylococci and Micrococci.

\section{T. Parker, Secretary} Phyllis M. Rountree, Chairman

\section{LITERATURE CITED}

1. Blair, J. E., and R. E. O. Williams. 1961. Bull. Wld. HIth. Org. 24:771.
2. Bülow, P. 1968. Acta Pathol. Microbiol. Scand. 72:147, 160, 543.

3. Bülow, P. 1970. Acta Pathol. Microbiol. Scand. 78:29.

4. Nakagawa,M. 1960. Jap. J. Vet. Res. 8:331.

5. Popovici, M., E. Alexenco, and I. Vianu. 1969. Arch. Roum. Pathol. Exp. Microbiol. 28:1032.

6. Report. 1967. Int. J. Syst. Bacteriol. 17:113.

7. Seto, J. T., and J. B. Wilson. 1958. Amer. J. Vet. Res. 19:241.

8. Smith, H. W. 1948. J. Hyg. Cambridge 46:74. 